\title{
Reproductive biology of invasive lionfish (Pterois spp.)
}

\author{
Patrick G. Gardner ${ }^{1}$, Thomas K. Frazer ${ }^{1,2}$, Charles A. Jacoby ${ }^{2,3}$ and Roy P. E. Yanong ${ }^{4}$ \\ ${ }^{1}$ Fisheries and Aquatic Sciences Program, School of Forest Resources and Conservation, University of Florida, Gainesville, FL, USA \\ ${ }^{2}$ School of Natural Resources and Environment, University of Florida, Gainesville, FL, USA \\ ${ }^{3}$ Soil and Water Science Department, University of Florida, Gainesville, FL, USA \\ ${ }^{4}$ Tropical Aquaculture Laboratory, Fisheries and Aquatic Sciences Program, School of Forest Resources and Conservation, University of Florida, Gainesville, \\ FL, USA
}

\section{Edited by:}

Pamela J. Schofield, US Geological Survey, USA

\section{Reviewed by:}

Aldo Cróquer, Simon Bolivar University, Venezuela

Jonathan M. Shenker, Florida Institute of Technology, USA William Frank Patterson III, University of South Alabama, USA

\section{${ }^{*}$ Correspondence:}

Patrick G. Gardner, Fisheries and Aquatic Sciences, University of Florida, 7922 NW 71st St.

Gainesville, FL 32653, USA e-mail: patgardner@ufl.edu
Indo-Pacific lionfishes, Pterois volitans (Linnaeus, 1758) and Pterois miles (Bennett, 1828), native to the Pacific and Indian Oceans, respectively, were first observed in the western Atlantic off Florida in 1985. They have since spread and are established throughout the broader Caribbean region. Despite potentially devastating ecological and economic effects, information on key life history characteristics for lionfish in the invaded range is sparse. Objectives of this study were to quantify (1) periodicity in gonad development and spawning, (2) spawning frequency, (3) batch fecundity and (4) female size at maturity for fish from Little Cayman. Calculation of gonadosomatic indices, histological and macroscopic staging of gonads, and counts of hydrated oocytes were applied to determine reproductive characteristics. Higher gonadosomatic indices were recorded for females during periods of stable warm or cool water temperatures indicating that extreme temperatures did not constrain reproduction. Histological and macroscopic staging suggested that male and female lionfish were capable of reproducing year-round. However, higher gonadosomatic indices in females, as expected before spawning, were most pronounced in March/April and August. Based on the proportion of females containing hydrated oocytes, mature lionfish had the potential to spawn every 2-3 days. Ovaries of mature females contained 1800-41945 oocytes that were hydrated in preparation for spawning, with greater numbers of oocytes in larger females. Female lionfish matured at $189-190 \mathrm{~mm}$ total length. Parameters estimated in this study can improve outputs from population dynamic models, which will help resource managers design removals and other efforts to control invasive lionfish.

Keywords: spawning frequency, batch fecundity, histology, maturity, gonadosomatic index

\section{INTRODUCTION}

Threats to coral reefs worldwide include global warming, overfishing, habitat destruction, and coastal pollution. In the Caribbean and western Atlantic, coral reefs also have been invaded by lionfishes Pterois volitans (Linnaeus, 1758) and Pterois miles (Bennett, 1828), native to the Pacific and Indian Oceans, respectively (Kulbicki et al., 2012). These Pterois spp. were first observed in the western Atlantic off Florida in 1985 (Morris and Akins, 2009), and they have since spread throughout the Caribbean and Gulf of Mexico (Schofield et al., 2013). Specimens also have been captured in the Mediterranean (Golani and Sonin, 1992; Bariche et al., 2013). In 2008, lionfish were observed in the waters surrounding Little Cayman Island, and they were considered established there by 2009 (Schofield, 2009). At this location, they have reached densities of up to $650 \mathrm{fish} \mathrm{ha}^{-1}$ (Frazer et al., 2012), which is far greater than the 26.3 fish ha $^{-1}$ recorded in the native range (Kulbicki et al., 2012).

In the Caribbean and western Atlantic, the spread of lionfish exacerbates concern for the health of coral reefs already threatened by other stresses. For example, manipulative field studies in the Bahamas have shown that lionfish can reduce recruitment of native reef fish by up to $79 \%$, with predation being the likely mechanism (Albins and Hixon, 2008). After lionfish invaded a mesophotic reef, Lesser and Slattery (2011) reported a shift from coral and sponge communities to algal dominated communities. Increased predation on herbivorous fish was implicated as the cause of the shift because it was not associated with bleaching, fishing, storms and disease (Lesser and Slattery, 2011). Effective management of the threats posed by lionfish, or any invasive species, requires knowledge of how reproductive characteristics support its persistence and spread (Sakai et al., 2001), but such information is generally lacking for Pterois spp.

Qualitative aspects of Pterois spp. reproduction have been described. Ovarian morphologies of $P$. volitans and $P$. miles are categorized as cystovarian type II-3, with a deep ovarian stroma, intermediate ovarian cavity, and superficial ovarian wall (Koya and Muñoz, 2007; Morris et al., 2011b). They have asynchronous oocyte development and indeterminate fecundity (Morris et al., 2011b). Oocytes are connected to the ovarian stroma by vascularized peduncles, which provide nutritive support (Hoar, 1969) and prevent overcrowding by lengthening as oocytes develop so that mature oocytes move to the periphery of the ovarian cavity (Fishelson, 1975). In preparation for spawning, cells lining the ovarian cavity produce a hollow, gelatinous egg mass (Koya and 
Muñoz, 2007). The egg mass is released during spawning, it protects the eggs and embryos (Erikson and Pikitch, 1993), and it may increase fertilization success (Morris et al., 2011b). In P. miles (formerly considered $P$. volitans), spawning followed courtship (Fishelson, 1975). Courtship began shortly after sundown when the males were observed leading females to the surface. Each female then released a floating egg mass that was fertilized by the male (Fishelson, 1975). Spawning behavior has not been described for $P$. volitans.

An initial quantitative evaluation of reproduction was conducted on $P$. volitans and $P$. miles from the western Atlantic. Morris (2009) reported that females matured at approximately $175 \mathrm{~mm}$ total length or 1 year of age and released approximately 25000 eggs per spawning event. Based on the presence of hydrated oocytes, mature females appeared capable of spawning every 3.6-4.1 days throughout the year, although the proportion of females with ovaries in spawning condition was higher in summer (June-August). In contrast, the condition of testes in mature males, fish $\geq 100 \mathrm{~mm}$ total length, exhibited less variation throughout the year.

Quantitative analyses of reproductive characteristics for lionfish from the Caribbean will enhance our understanding of how reproduction supports the spread and establishment of this invader. In addition, this information will provide valuable guidance for efficient and effective management responses to protect this region's coral reefs. Thus, the overall objective of this study was to quantify reproductive characteristics of lionfish in the central Caribbean. Specific metrics to be estimated were (1) periodicity in gonad development and spawning season, (2) spawning frequency, (3) batch fecundity and (4) female size at maturity. From this point, "lionfish" and Pterois spp. refer to $P$. volitans and $P$. miles, with due recognition that $P$. volitans dominates abundances in the invaded range (Hamner et al., 2007).

\section{MATERIALS AND METHODS \\ PERIODICITY IN GONAD DEVELOPMENT AND SPAWNING SEASON}

Gonadosomatic indices (GSIs), pre-fixation macroscopic staging and histological staging were used to determine periodicity in gonad development for lionfish. Pterois spp. from the waters surrounding Little Cayman were provided by local divemasters and volunteers. From January 2011 to August 2012, divers on open circuit SCUBA speared or netted lionfish between 1700 and $1900 \mathrm{~h}$ when the fish tended to forage or reproduce (Fishelson, 1975; Green et al., 2011; Kulbicki et al., 2012). After capture, fish were transported to a laboratory at the Central Caribbean
Marine Institute where they were stored in a refrigerator or on ice. Lionfish were processed the next morning. The total length of each fish was measured to the nearest $\mathrm{mm}$, and all individuals were weighed to the nearest $0.1 \mathrm{~g}$. After being removed, ovaries and testes were weighed to the nearest $0.0001 \mathrm{~g}$ and preserved in $10 \%$ neutral buffered formalin.

A gonadosomatic index was calculated for each fish by dividing its gonad mass by its total body mass and multiplying by 100 . Monthly variations in female and male GSIs were examined with One-Way analyses of variance (ANOVAs) on arcsine transformed data.

Further evidence of periodicity came from ovaries staged macroscopically according to a scheme adapted from Everson et al. (1989). From October 2011 to August 2012, ovaries were classified as (1) immature/resting, (2) developing, (3) ripe, and (4) spent (Table 1, Supplementary Material). The validity of visual staging was confirmed by histological analyses of female lionfish that spanned the range of masses and GSIs for each month during 2011-2012.

Additional histology characterized maturation phases and developmental stages of male and female lionfish. In all cases, longitudinal and transverse sections of preserved ovaries and testes were dehydrated in a series of solutions with increasing alcohol concentrations, embedded in paraffin, and sectioned $(4-6 \mu \mathrm{m})$ with a microtome (Pandey et al., 2008). Sections were mounted on slides and stained with hematoxylin and eosin before being examined at 40-400× magnification.

Maturation status was determined from histological sections using adaptive criteria developed by combining morphological characteristics and underlying regulatory endocrinology (Grier and Taylor, 1998; Grier et al., 2009). Testes were classified into maturation phases according to activity in the germinal epithelium (GE) and development of germ cells (Grier and Taylor, 1998). Five phases were recognized: regressed, early GE development, mid-GE development, late GE development, and regression (Table 2, Supplementary Material). Ovaries were classified into six oogenetic developmental stages: oogonial proliferation, chromatin-nucleolus formation, primary growth, secondary growth, oocyte maturation, and ovulation (Table 3, Supplementary Material). The presence of oocytes in multiple developmental stages meant that fish were assigned to a stage based on the most advanced oocyte observed (Grier et al., 2009). In addition, staging based on oocytes was augmented with observations of postovulatory follicles (POFs), comprising the remains of follicles and the surrounding basement membrane and theca left after ovulation, and observations of atresia, characterized

Table 1 | Macroscopically determined maturity stages for pre-fixation ovaries, adapted from Everson et al. (1989).

\begin{tabular}{|c|c|c|}
\hline Macroscopic maturity stage & Description & Brown-Peterson et al. (2011) phase \\
\hline Immature/resting & $\begin{array}{l}\text { Ovaries small and pink, ovarian wall thin, no well-developed blood vessels, } \\
\text { no oocytes distinguishable }\end{array}$ & Immature \\
\hline Developing & Ovary large, oocytes visible and tightly packed & Developing \\
\hline Ripe & $\begin{array}{l}\text { Gelatinous egg mass formed, ovaries reach maximum size, blood vessels } \\
\text { distinct, transparent oocytes seen dispersed throughout egg mass }\end{array}$ & Spawning capable \\
\hline Spent & Small, darkened ovaries, blood vessel developed & Regressing, regenerating \\
\hline
\end{tabular}


Table 2 | Maturation phases for histological analysis of male fish based on the activity of the germinal epithelium (GE) and the development of germ cells, with terms and phases based on Grier and Taylor (1998).

\begin{tabular}{|c|c|c|}
\hline Development phase & Description & $\begin{array}{l}\text { Brown-Peterson et al. (2011) } \\
\text { phase }\end{array}$ \\
\hline Early GE development & Spermatocysts form; continuous, active GE & Developing \\
\hline Mid-GE development & $\begin{array}{l}\text { Sperm released from spermatocysts, discontinuous GE beginning at proximal ends of } \\
\text { lobule, continuous distally }\end{array}$ & Developing \\
\hline Late GE development & Proximal ends of lobule filled with sperm, at least one lobule discontinuous at the terminus & Spawning capable \\
\hline Regression & Few, scattered spermatocysts, sperm fills lobule to termini & Regressing \\
\hline Regressed & Primary and secondary spermatogonia, continuous GE along the entire length of lobule & Regenerating \\
\hline
\end{tabular}

Table 3 | Developmental stages for histological analysis of female fish based on applying criteria developed by Grier et al. (2009) to the most advanced oocytes observed and the presence of post-ovulatory complexes.

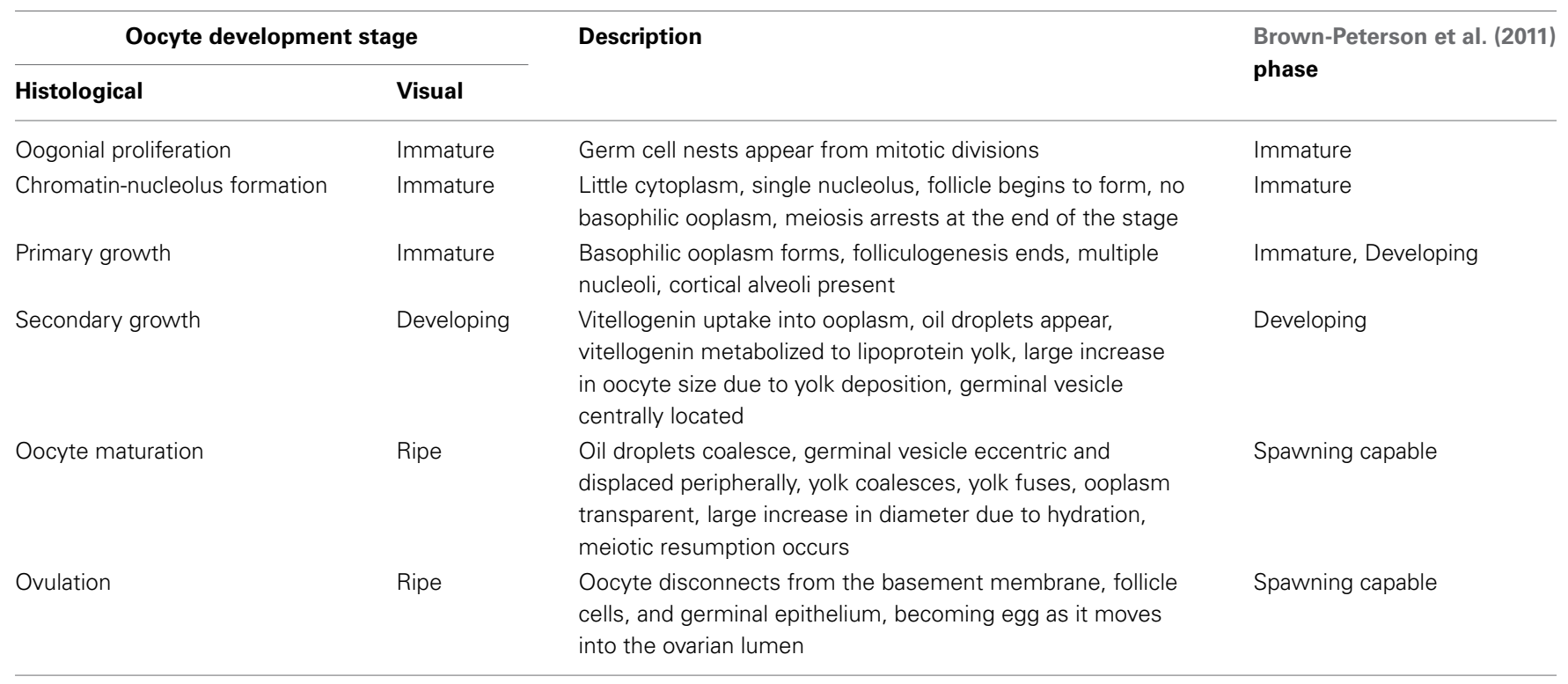

Histological stages translated to corresponding visual stages.

by degeneration and subsequent phagocytosis of follicles (Grier, 2012).

Spawning periodicity was determined by combining GSIs, macroscopic staging, and histological staging. Spawning was considered likely in months when fish had higher GSIs and months when numerous females were categorized as ripe by macroscopic staging or undergoing oocyte maturation as determined by histological staging. To assess the relationship between water temperature and gonad maturation, monthly water temperatures at a depth of $4.6 \mathrm{~m}$ were obtained from an Integrated Coral Observing Network (ICON) weather station on the north side of the island.

\section{SPAWNING FREQUENCY}

Estimates of spawning frequency were based on fish collected between 1830 and 1915 h on 9 days between 7 and 16 May 2012 . During this time, water temperatures ranged from 26 to $27^{\circ} \mathrm{C}$. Fish were collected from different sites each day in an attempt to account for spatial variation at the local scale. After capture, fish were transported to the laboratory, placed on ice, and processed within $6 \mathrm{~h}$. Total lengths of all fish were measured to the nearest $\mathrm{mm}$, and wet mass was recorded to the nearest $0.1 \mathrm{~g}$. Ovaries were staged macroscopically, removed, weighed to the nearest $0.0001 \mathrm{~g}$, and preserved in $10 \%$ neutral buffered formalin, which caused hydrated oocytes to become cloudy.

Spawning frequency was calculated with the mature oocyte method (Hunter and Macewicz, 1985; Morris, 2009; McBride et al., 2012). Accordingly, mature female fish were categorized as ready to spawn if hydrated oocytes were present (Collins et al., 2001; Almatar et al., 2004). Spawning frequency in d was calculated as the inverse of the spawning fraction, i.e., the quotient of the number of mature females and the number of fish prepared to spawn as indicated by the presence of hydrated oocytes.

Oocyte diameters were measured to aid in the identification of synchrony or asynchrony in oocyte development, differentiation of determinate and indeterminate fecundity and characterization of changes in morphology during oocyte maturation. Photographs of histologically prepared slides taken at 100-400x were imported into i-Solution ${ }^{\mathrm{TM}}$ software, and five fields of view were haphazardly chosen. In each field of view, oocytes chosen for measurement were identified by stage (primary growth, 
secondary growth and oocyte maturation) and measured along the longest axis that passed through their germinal vesicles to ensure measurements accurately represented diameters. Oocyte diameters were $\log _{10}$-transformed, and ANOVA was used to evaluate significant differences in diameters among stages, individual fish nested in stages, and fields of view nested in stages and fish.

\section{BATCH FECUNDITY}

Batch fecundity constituted the total number of hydrated oocytes likely to be released per spawning event, with lionfish sampled in winter (October, November, and December 2011) and summer (May 2012) to evaluate seasonal variation. Ovaries with hydrated oocytes were preserved in 10\% neutral buffered formalin. After preservation, the entire ovary was agitated with a stir bar and broken apart with forceps. Connective tissue was removed, and the volume of the remaining sample was measured before three, 1-mL subsamples were withdrawn using a Hensen-Stempel pipette. A photograph of each subsample was taken at $10 \times$ magnification using a dissecting stereoscope. Hydrated oocytes appeared translucent when subjected to transmitted light (Karlou-Riga and Economidis, 1997; McBride et al., 2002), so they were easily enumerated with the assistance of the "cell counter" plugin for ImageJ (http://rsbweb.nih.gov/ij/; Ganias et al., 2008). Counts from subsamples were scaled to estimate total batch fecundity where $N_{T}$ was total batch fecundity, $N_{S}$ was the oocyte count in a subsample, $V_{1 / 2 T}$ was the volume of material from one ovary, and $V_{S}$ was the volume of a subsample. Counts from subsamples of ovaries were volumetrically scaled to whole ovaries because the gelatinous matrix surrounding hydrated oocytes interfered with gravimetric scaling. For four fish, batch fecundity was estimated independently using both ovaries as a means of evaluating the accuracy of estimates based on counts from a single ovary. Differences in batch fecundity between the two sampling periods were evaluated with analyses of covariance (ANCOVAs) based on either total length or total mass.

$$
N_{T}=2 \times \frac{N_{S} \times V_{\frac{1}{2} T}}{V_{S}}
$$

\section{FEMALE SIZE AT MATURITY}

Average female size at maturity was estimated in two ways. The theoretical zero egg production method estimated size at maturity as the total length at which egg production was theoretically zero, as determined from a linear regression of batch fecundities against total lengths (McBride et al., 2002). Using records from different fish, the logistic fit method estimated size at maturity from histological and macroscopic staging. Histologically staged fish were deemed mature if their most advanced oocytes were in secondary growth or maturation. Macroscopically staged fish were deemed mature if they had developing, ripe, or spent ovaries. Immature/resting fish, considered non-reproductive, were assigned a 0 while mature fish were assigned a value of 1 . A multi-parameter logistic function was fit to the resulting binomial data where $P$ (mat) was the probability of maturity, $T L$ was total length, $L_{50}$ mat was the length at which $50 \%$ of the fish were mature, and sigma $(\sigma)$ was a parameter characterizing the slope of the fitted curve. The parameters were estimated by maximizing the negative log-likelihood function in $\mathrm{R}$ software version 2.12.1.

$$
P(m a t)=\frac{1}{1+e^{\left(T L-L_{50} m a t\right) / \sigma}}
$$

\section{RESULTS}

\section{PERIODICITY IN GONAD DEVELOPMENT AND SPAWNING SEASON}

Gonadosomatic indices were calculated for 835 females and 1029 males captured between January 2011 and August 2012. GSI values varied significantly by month for both females [ANOVA, $\left.F_{(18,816)}=4.92, P<0.001\right]$ and males [ANOVA, $F_{(18,1010)}=$ $5.49, P<0.001]$. Back-transformed monthly mean female GSI [95\% confidence limits] ranged from $1.96[1.82,2.10]$ to 6.19 $[5.97,6.42]$, while back-transformed mean male GSI ranged from $0.0301[0.0291,0.0312]$ to 0.0564 [0.0522, 0.0608].

In general, the highest GSI values occurred during or immediately following the months with maximum or minimum mean temperatures for each year, which only differed by $4^{\circ} \mathrm{C}$ (Figure 1). In addition, lower monthly mean GSI values occurred during months when temperatures were changing rapidly. For example, one of the largest temperature changes occurred between October

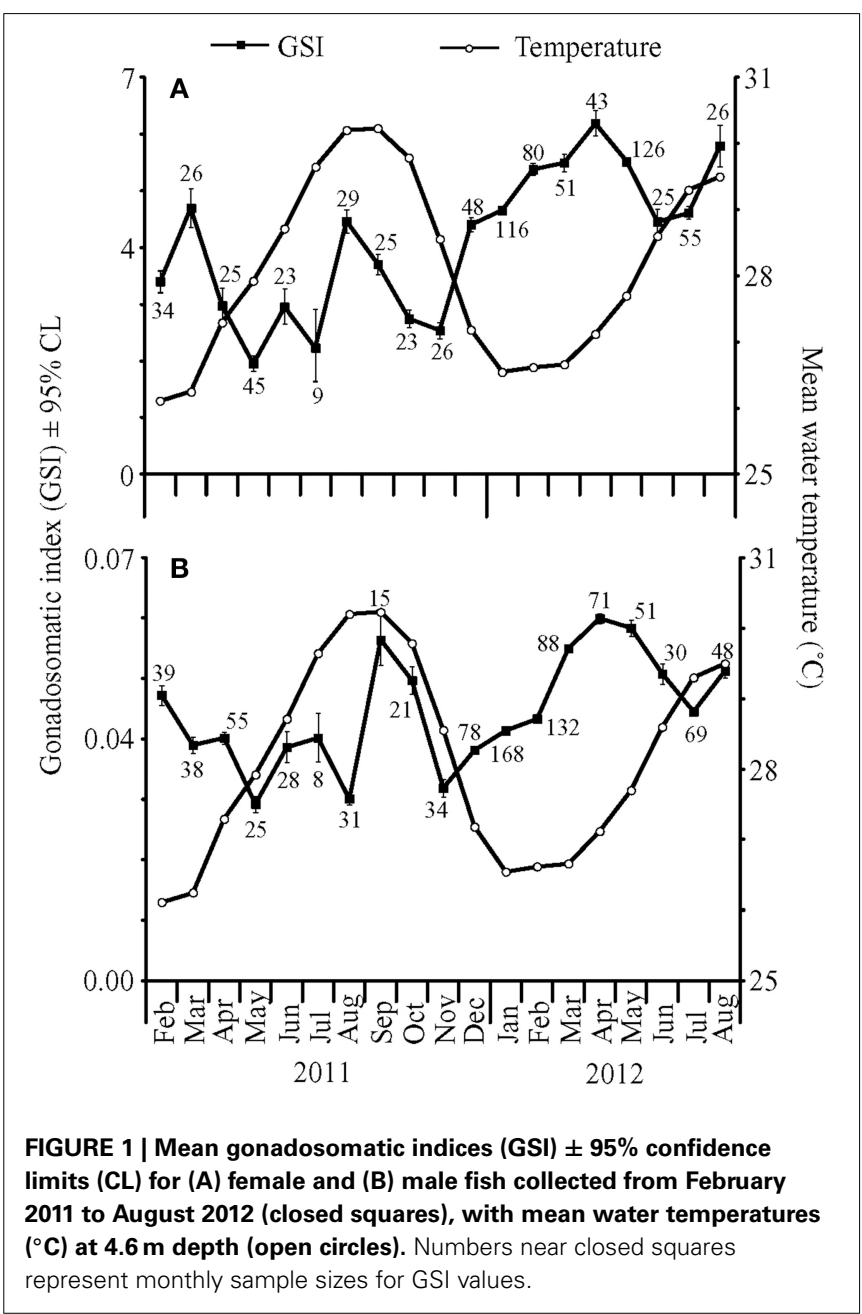




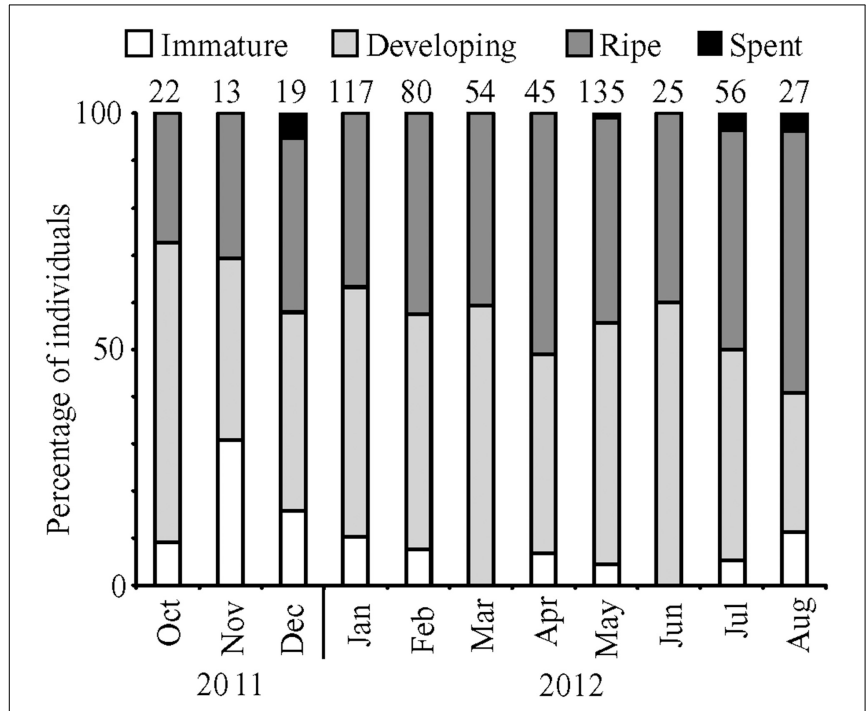

FIGURE 2 | Percentage of female fish in each development stage for months from October 2011 to August 2012. Numbers above bars represent monthly sample sizes.

and November 2011. During this time, both male and female GSI values were low. In 2011, mean female GSI peaked in March and August. Corresponding peaks in male GSI were observed in February and September-October. In 2012, female GSI peaked in April and August, whereas maximum GSI values for males were recorded in April-May. Overall, both male and female GSI values followed similar patterns with higher values from January to April, lower values from April to June-July, and higher values in August and September.

In total, 593 female fish were staged visually between October 2011 and August 2012 (Figure 2). The median GSI values for immature/resting, developing, and ripe fish were $0.4,3.3$, and 9.9, respectively. Most of the fish were characterized as developing (50\%) followed by ripe (42\%), immature/resting (7\%) and spent (1\%). Similar to histological staging, maximum GSI values corresponded to a high prevalence of ripe fish in combination with a low prevalence of non-reproductive fish.

Monthly subsamples of 7-13 female lionfish yielded 39 fish for histological confirmation of visual staging. Overall, macroscopic staging was highly reliable (97\% accurate) for determining whether or not a female fish was mature (immature/resting vs. developing or ripe). Agreement between histological and macroscopic staging was $89 \%$ for immature/resting fish (8 of 9), $84 \%$ for developing fish (22 of 26), and 75\% for ripe fish (3 of 4).

Histological staging also was performed on 107 ovaries collected from January to December 2011 plus 14 ovaries collected in January and February 2012. Total lengths of the female fish ranged from 131 to $305 \mathrm{~mm}$, with the majority of fish having oocytes in secondary growth (45\%) followed by oocyte maturation $(35 \%)$ and primary growth (21\%; Figure 3A). The months with high GSI values corresponded to months with a high prevalence of maturing oocytes, including oocytes in late maturation, and a low prevalence of oocytes in primary growth. The highest GSI values occurred in March and August 2011, when histological staging

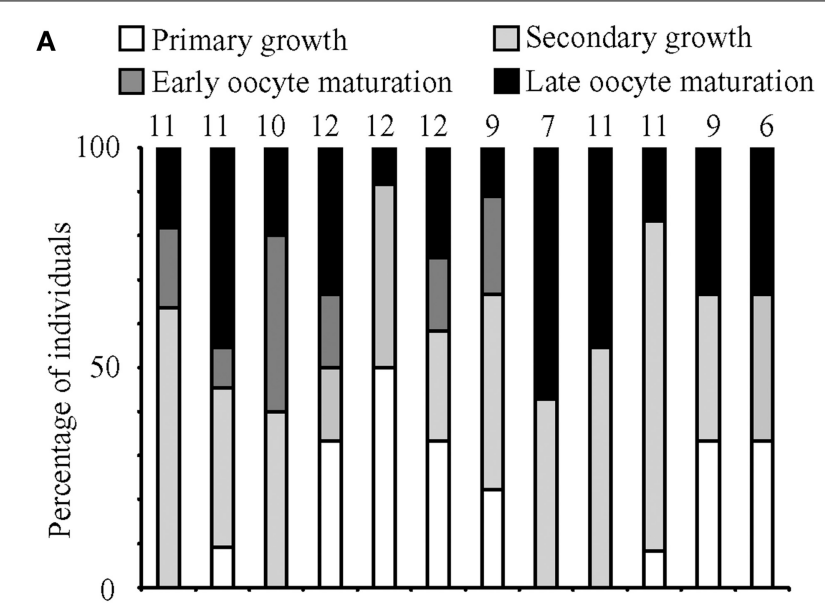

B

$\square$ Regressed
$\square$ Mid GE development
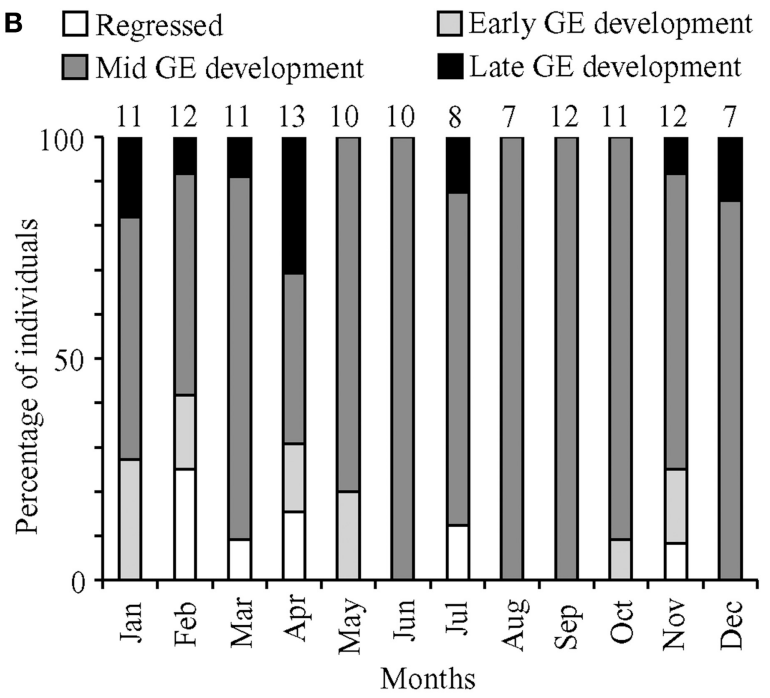

FIGURE 3 | Percentage of (A) female and (B) male fish in the most advanced development stage or maturation phase observed, respectively, for months from January to December 2011. Numbers above bars represent monthly sample sizes.

identified the highest proportion of maturing females and no fish in primary growth. Conversely, the months with the lowest GSI values corresponded to months with relatively high prevalence of oocytes in primary growth and low prevalence of maturing oocytes. POFs were present in $13(\sim 10 \%)$ of the histologically staged females in the months of January, February, April, June, July, August, September, and they were observed only in fish prepared to spawn as evidenced by the predominance of oocytes in late maturation. Atretic follicles were present in less than $5 \%$ of all female lionfish examined.

Based on histological staging, females in oocyte maturation were found in every month except December, and macroscopic staging revealed ripe females in every month. These data suggested that females spawn year-round. The prevalence of males in mid and late GE development also indicated a capacity for year-round spawning. However, GSI calculations indicated that lionfish spawning was most pronounced in March/April and August. 
Histological staging was performed on 112 testes collected in 2011, with an additional 12 testes collected in January and April 2012. These testes came from fish with total lengths ranging from 157 to $384 \mathrm{~mm}$. The histological data for males yielded no clear patterns corresponding to minimum and maximum GSI values (Figure 3B). There was a high prevalence of fish in mid-GE development $(75 \%)$. Monthly proportions were consistently low for regressed (0-25\%), early GE development (0-27\%), and late GE development (0-31\%).

\section{SPAWNING FREQUENCY}

Estimates of spawning frequency were based on 107 mature females (i.e., developing or ripe) ranging from 190 to $372 \mathrm{~mm}$ total length and 78.1 to $721.6 \mathrm{~g}$ wet mass. Of these, 45 had hydrated oocytes, which yielded an overall spawning frequency of 2.4 days. The spawning fraction varied among days, ranging from 0.00 to 0.57 (Table 4).

In fish with maturing or mature oocytes, size-frequency distributions of oocyte diameters were continuous and without any interlude, which indicated asynchronous development and suggested indeterminate fecundity (Figure 4). Mean oocyte diameters were significantly different among fish in different stages [primary growth, secondary growth and maturation; ANOVA, $\left.F_{(2,141)}=106.91, P<0.001\right]$, with the choice of the denominator in the $F$-test accounting for a significant difference among fields of view [ANOVA, $\left.F_{(141,3203)}=11.22, P<0.001\right]$. No significant differences were detected in oocyte diameters among fish within a given stage [ANOVA, $\left.F_{(35}, 141\right)=1.16, P=0.267$ ] Fish categorized as exhibiting only primary growth had oocytes smaller than $129 \mu \mathrm{m}$ in diameter. Fish exhibiting secondary growth also had oocytes ranging up to $464 \mu \mathrm{m}$ in diameter, and fish preparing to spawn had additional oocytes ranging up to $638 \mu \mathrm{m}$ in diameter.

\section{BATCH FECUNDITY}

For two fish from both the winter and summer sampling periods, independent estimates of batch fecundity for both ovaries yielded coefficients of variation (CVs) ranging from 1.0 to $11.3 \%$ (Table 5). Thus, the counts performed on a single ovary were

Table 4 | Daily spawning fraction and spawning frequency for fish collected from 7 through 16 May 2012.

\begin{tabular}{lcccc}
\hline Date & $\begin{array}{c}\text { Mature } \\
\text { females }\end{array}$ & $\begin{array}{c}\text { Females with } \\
\text { hydrated oocytes }\end{array}$ & $\begin{array}{c}\text { Spawning } \\
\text { fraction }\end{array}$ & $\begin{array}{c}\text { Spawning } \\
\text { frequency }\end{array}$ \\
\hline 7 & 4 & 1 & 0.25 & 4.00 \\
8 & 16 & 4 & 0.25 & 4.00 \\
9 & 13 & 5 & 0.38 & 2.60 \\
10 & 3 & 1 & 0.33 & 3.00 \\
11 & 11 & 6 & 0.55 & 1.83 \\
12 & 13 & 5 & 0.38 & 2.60 \\
14 & 30 & 17 & 0.57 & 1.76 \\
15 & 11 & 6 & 0.55 & 1.83 \\
16 & 6 & 0 & 0.00 & - \\
All fish & 107 & 45 & 0.42 & 2.38 \\
\hline
\end{tabular}

No fish were sampled on 13 May. considered reliable, and the means of these paired estimates were incorporated into ANCOVAs with values from single ovaries.

For nine fish from winter sampling and 12 fish from summer sampling, total batch fecundity ranged from 1800 to 41945 hydrated oocytes for fish with total lengths of 204-332 $\mathrm{mm}$ and wet masses of 103.2-460.4 g (Figure 5). Raw batch fecundity data violated ANCOVA assumptions, so data were $\log _{10}$-transformed, and one outlier was removed (Cook's $D=2.67$ ). Batch fecundity

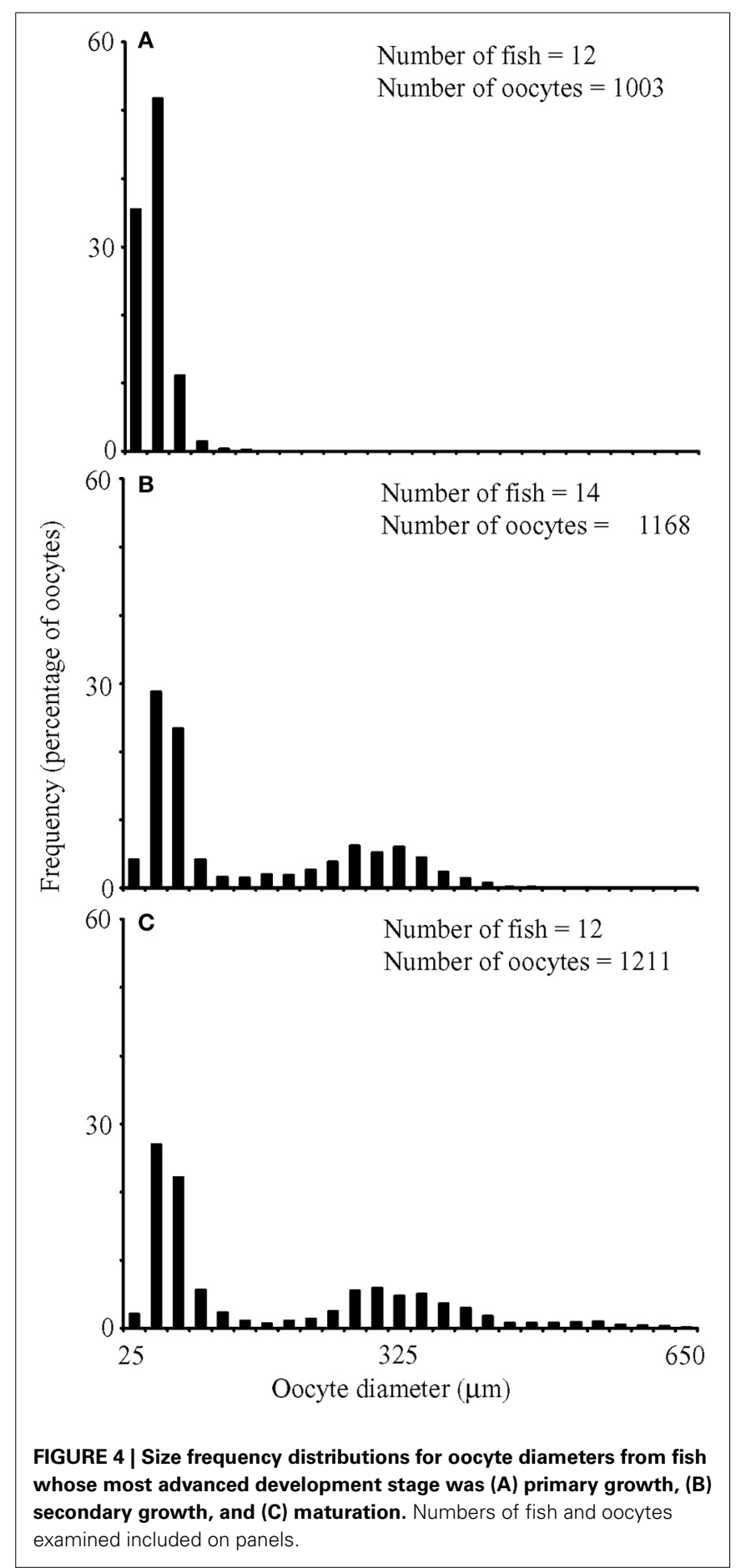


Table 5 | Independently estimated batch fecundities from left and right ovaries.

\begin{tabular}{lcccc}
\hline Fish & $\begin{array}{c}\text { Total } \\
\text { length }(\mathbf{m m})\end{array}$ & $\begin{array}{c}\text { Total gonad } \\
\text { mass } \mathbf{( g )}\end{array}$ & $\begin{array}{c}\text { Batch fecundity } \\
\text { (hydrated oocytes) }\end{array}$ & CV (\%) \\
\hline Winter fish 1 & 263 & 17.4247 & $\begin{array}{c}10776 \\
9184\end{array}$ & 11.3 \\
Winter fish 2 & 247 & 14.3881 & 12489 & 5.8 \\
& & & 11506 & \\
Summer fish 1 & \multirow{2}{*}{332} & 52.9509 & 24732 & 1.0 \\
& & & 24378 & \\
Summer fish 2 & 284 & 32.7054 & 43296 & 4.6 \\
& & & 40594 & \\
\end{tabular}

$C V$, coefficient of variation.

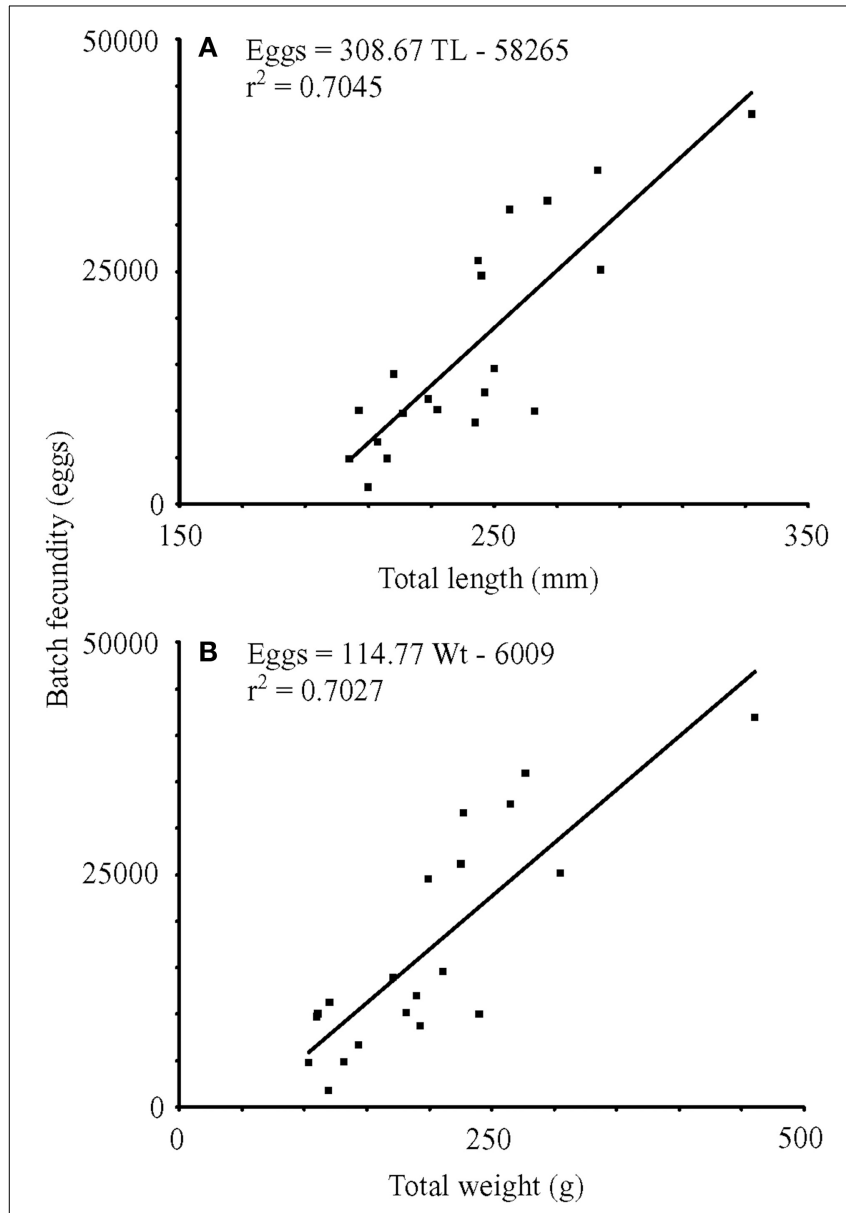

FIGURE 5 | Linear regressions of batch fecundity vs. (A) total length $(\mathbf{m m})$ and (B) wet mass $(\mathbf{g})$. TL, total length $(\mathrm{mm})$; $W \mathrm{t}$, wet mass $(\mathrm{g}) ; \mathrm{r}^{2}$, coefficient of determination.

increased significantly with total length [ANCOVA, $F_{(1,17)}=$ 19.71, $P<0.001$ ] and total mass [ANCOVA, $F_{(1,17)}=35.54$, $P<0.001]$, but season had no significant effect in combination with either total length [ANCOVA, $F_{(1,17)}=1.70, P=0.210$ ] or total mass [ANOVA, $F_{(1,17)}=0.04, P=0.851$ ].

\section{FEMALE SIZE AT MATURITY}

The two approaches to estimating female size at maturity yielded nearly identical values. The theoretical zero egg production method resulted in an estimate of $189 \mathrm{~mm} \mathrm{TL}$, and the logistic model estimated the length at 50\% maturity [ $95 \%$ confidence limits] to be $190[184,197] \mathrm{mm}$ TL, with sigma being 13.1 .

\section{DISCUSSION}

Results of this study yielded five key insights into reproduction of invasive lionfish in the central Caribbean. The first records of GSI values for lionfish and histological staging of ovaries indicated two major spawning periods per year, which coincided with periods of relatively stable water temperatures in March/April and August. Thus, it appears that lionfish reproduction was affected by temperature even though the range $\left(4^{\circ} \mathrm{C}\right)$ was much narrower than that experienced by temperate fishes. At the population level, male and female lionfish remained capable of reproducing yearround as shown by staging of ovaries and testes, presence of hydrated oocytes, and infrequent observations of oocyte atresia. The proportion of females containing hydrated oocytes indicated that, once mature, lionfish were capable of spawning as frequently as every $2-3$ days. Based on counts of hydrated oocytes, mature females preparing to spawn were capable of releasing 1800-41945 eggs during each event, with greater numbers of eggs released by larger females. Estimated size at maturity for female lionfish was $189 \mathrm{~mm}$ TL based on the theoretical zero egg production method and $190 \mathrm{~mm}$ TL according to a logistic model fit to data from histological and macroscopic staging.

Although lionfish appeared capable of spawning throughout the year, reproductive effort did vary within each year of sampling. Within years, males and females generally allocated resources to gonad enlargement at the same time. Female GSI values varied more widely and exhibited a clearer monthly pattern, a phenomenon also reported for other fish (e.g., the dolphinfish, Coryphaena hippurus, Alejo-Plata et al., 2011). Given that reproductive effort was high at times of both minimum and maximum water temperatures (August-October and January-March), this study suggested that temperature extremes in the central Caribbean did not constrain lionfish reproduction. Since lionfish are found throughout the equatorial Indo-Pacific (Kulbicki et al., 2012), data from the northern and southern boundaries of their native range may provide estimates of thermal limits to spawning.

Data from a complementary study determined that mean mass of lionfish stomach contents were highest in the months of December and September (Edwards, 2012). These results indicated that lionfish increased feeding in the months between likely periods of reproduction, which may have allowed energy reserves to be replenished (Fordham and Trippel, 1999). Although food availability and water temperature often represent key cues for spawning, it is likely that other factors, including photoperiod, tidal cycle, and moon phase, also affect spawning cycles (Taylor, 1984; Sala et al., 2003; Heyman et al., 2005). Ultimately, evolutionary consequences from reproduction are likely to yield spawning cycles that optimize adult fitness, larval survival, and recruitment success (Robertson, 1990).

The population of lionfish contained individuals capable of reproducing throughout the year as evidenced by visual and 
histological staging of testes and ovaries, along with measurements of oocyte diameters. Across all months of sampling, the majority of male fish were in mid-GE development, with few individuals being in the regressed or early GE development phases. Similarly, females with maturing oocytes and ripe ovaries were present consistently. Furthermore, size frequency distributions of oocytes indicated that females remained capable of spawning due to asynchronous development of oocytes. In fact, mature females appeared to cycle through a non-reproductive state quickly as evidenced by the low occurrence of both atretic oocytes and POFs, which should have been left behind after oocytes were ovulated into the gelatinous egg mass. A lack of POFs led Morris (2009) to conclude that the postovulatory follicle method was an unreliable way to estimate spawning frequency in lionfish. In this study, POFs were found only in fish with hydrated oocytes that were captured in the late afternoon, which suggested that these females were undergoing ovulation in preparation for spawning the night of capture (Fishelson, 1975). The limited occurrence of POFs suggested that these complexes were resorbed within $12 \mathrm{~h}$, with resorption being primarily a temperature dependent process (Hunter and Macewicz, 1985; Fitzhugh and Hettler, 1995). Alternatively, release of the gelatinous egg mass may have carried away most POFs. Further studies are necessary to provide insights into the mechanics of spawning a gelatinous egg mass.

The estimate of spawning frequency reported here, 2.41 days on average, was representative of lionfish spawning on shallow reefs ( $\sim 30$ m or less) around Little Cayman Island during a short time when GSI values for mature females were relatively high, but not at the maximum observed. Morris (2009) estimated spawning frequency as every 3.6 days in the Bahamas and 4.1 days in North Carolina. In the laboratory, Yoneda et al. (2000) spawned Scorpaenodes littoralis, a closely related scorpaenid with a similar ovarian structure and a gelatinous egg mass. Under ideal conditions, $S$. littoralis spawned every 2 days over $4-8$ months, with one fish spawning 118 times in 8 months, to yield a spawning frequency of $\sim 2$ days (Yoneda et al., 2000). Thus, it is reasonable to assume that lionfish have the capacity to spawn every 2-3 days. In fact, estimates generated during periods of maximum GSI values may suggest more frequent spawning.

Batch fecundity estimates of 1800-41945 eggs for lionfish off Little Cayman Island were derived from females that were 204-332 mm TL. Batch fecundity of lionfish collected off North Carolina, 24630 eggs per spawn (Morris, 2009), fell within our estimated range. In addition, lionfish batch fecundity was similar to that of a smaller scorpionfish, Scorpaena notata (Muñoz et al., 2005). Both fish possess cystovarian type II-3 ovaries specialized to produce gelatinous egg masses (Muñoz et al., 2005; Morris, 2009). Batch fecundity of the small red scorpionfish ranged from 6000 to 33000 eggs for individuals from 94 to $152 \mathrm{~mm}$ standard length (Muñoz et al., 2005). Muñoz et al. (2005) suggested that batch fecundity of scorpaenids with gelatinous egg masses tend to be relatively low when compared to other oviparous fish in the scorpaeniform order (up to 108000 for Trigla lyra, Muñoz, 2001).

Batch fecundity for older, large-bodied reef fish in the western Atlantic and Caribbean can be more than an order of magnitude greater than the estimates for lionfish, e.g., up to 865295 eggs per synchronized spawning event for gag grouper Mycteroperca microlepis (Collins et al., 1998), 2.3 million eggs for red grouper Epinephelus morio (Collins et al., 2002), and 3.4 million eggs for red snapper Lutjanus campechanus (Collins et al., 2001). Lower batch fecundities for fish forming egg masses may be related to higher fertilization and hatching success for eggs held together in a gelatinous matrix (Morris, 2009). The lack of statistically significant differences in egg production between seasons could have been an artifact of low sample size and higher batch fecundities may be documented when female GSIs are at their maximum; therefore, further seasonal sampling is recommended before estimates of annual fecundity are undertaken.

Data from this study and Morris (2009) demonstrated that lionfish mature at approximately $40 \%$ of their maximum total lengths. Morris (2009) calculated that $50 \%$ of males were mature at $100 \mathrm{~mm} \mathrm{TL}$, and attempts to repeat this calculation were precluded by the fact that all male lionfish captured off Little Cayman Island were larger than this threshold. In this study, length at $50 \%$ maturity for females was estimated to be 189-190 mm TL, which was $15 \mathrm{~mm}$ longer than reported by Morris (2009). From age data gathered in a parallel study at Little Cayman Island, lionfish of $190 \mathrm{~mm}$ TL were between 0 and 2 years old (Edwards et al., 2014), which bracketed Morris' (2009) estimate of maturity at under 1 year old. Latitudinal and regional differences in environmental conditions, food supplies, or other biological and ecological factors may result in different values for average length at maturity and other reproductive parameters. Regardless, such relatively small differences may not be biologically significant, especially for lionfish that mature early (McBride et al., 2012).

While complete eradication of invasive lionfish is unlikely given existing approaches and tools, maintenance management, or well-planned, targeted lionfish removals, can ameliorate impacts on critical habitats or economically and ecologically important species (Frazer et al., 2012). Evaluations of potential management actions, including lionfish removals, can benefit from scenarios tested with models of population dynamics. To date, two studies have used modeling to predict responses of lionfish populations to removals (Barbour et al., 2011; Morris et al., 2011a). Both of these studies relied on parameters that were not derived from data on lionfish reproduction in the Caribbean. The results of this study could be incorporated into future models to improve the reliability and robustness of their outputs. Rigorous and accurate models will allow managers to predict how lionfish populations will respond to removals and help them devise clear, goal-oriented strategies to reduce negative impacts from this invasive species.

\section{ACKNOWLEDGMENTS}

We thank the resorts and dive staff on Little Cayman for allowing us to use the fish collected during their culling events and the Central Caribbean Marine Institute staff for assistance throughout this project. M. Edwards, S. Barry, N. van Niekerk, and R. Hedges were critical to the organization and execution of data collection. H. Grier provided training in fish reproduction and microanatomy, and J. Morris provided advice on evaluating batch fecundity and spawning frequency. This project was supported, in part, by the Disney World Wildlife Conservation Fund. 


\section{SUPPLEMENTARY MATERIAL}

The Supplementary Material for this article can be found online at: http://www.frontiersin.org/journal/10.3389/fmars. 2015.00007/abstract

\section{REFERENCES}

Albins, M. A., and Hixon, M. A. (2008). Invasive Indo-Pacific lionfish Pterois volitans reduce recruitment of Atlantic coral-reef fishes. Mar. Ecol. Prog. Ser. 367, 233-238. doi: 10.3354/meps07620

Alejo-Plata, C., Díaz-Jaimes, P., and Salgado-Ugarte, I. (2011). Sex ratios, size at sexual maturity, and spawning seasonality of dolphinfish (Coryphaena hippurus) captured in the Gulf of Tehuantepec, Mexico. Fish. Res. 110, 207-216. doi: 10.1016/j.fishres.2011.04.008

Almatar, S. M., Lone, K. P., Abu-Rezq, T. S., and Yousef, A. A. (2004). Spawning frequency, fecundity, egg weight and spawning type of silver pomfret, Pampus argentus (Euphrasen) (Stromateidae), in Kuwait waters. J. Appl. Ichthyol. 20, 176-188. doi: 10.1111/j.1439-0426.2004.00546.x

Barbour, A. B., Allen, M. S., Frazer, T. K., and Sherman, K. D. (2011). Evaluating the potential efficacy of invasive lionfish (Pterois volitans) removals. PLoS ONE 6:e19666. doi: 10.1371/journal.pone.0019666

Bariche, M., Torres, M., and Azzurro, E. (2013). The presence of the invasive lionfish (Pterois miles) in the Mediterranean Sea. Mediterr. Mar. Sci. 14, 292-294. doi: $10.12681 / \mathrm{mms} .428$

Brown-Peterson, N. J., Wyanski, D. M., Saborido-Rey, F., Macewicz, B. J., and Lowerre-Barbieri, S. K. (2011). A standardized terminology for describing reproductive development in fishes. Mar. Coast. Fish. 3, 52-70. doi: $10.1080 / 19425120.2011 .555724$

Collins, L. A., Fitzhugh, G. R., Lombardi-Carlson, L. A., Lyon, H. M., Walling, W. T., and Oliver, D. W. (2002). Characterization of Red Grouper (Serranidae: Epinephelus morio) Reproduction from the Eastern Gulf of Mexico. Panama City, National Marine Fisheries Service, Southeast Fisheries Center.

Collins, L. A., Fitzhugh, G. R., Mourand, L. A., Lombardi, L. A., Walling, W. T. Jr., Fable, W. A. Jr., et al. (2001). Preliminary results from a continuing study of spawning and fecundity in the red snapper (Lutjanidae: Lutjanus campechanus) from the Gulf of Mexico, 1998-1999. Proc. 52nd Gulf Caribb. Fish. Inst. 52, 34-47.

Collins, L. A., Johnson, A. G., Koenig, C. C., and Baker, M. S. Jr. (1998). Reproductive patterns, sex ratio, and fecundity in gag, Mycteroperca microlepis (Serranidae), a protogynous grouper from the northeastern Gulf of Mexico. Fish Bull. 96, 415-427.

Edwards, M. A. (2012). Age, Growth, and Diet of Lionfish (Pterois spp.) From Little Cayman Island, B.W.I. thesis, University of Florida, Gainesville.

Edwards, M. A., Frazer, T. K., and Jacoby, C. A. (2014). Age and growth of invasive lionfish (Pterois spp.) in the Caribbean Sea, with implications for management. Bull. Mar. Sci. 90, 953-966. doi: 10.5343/bms.2014.1022

Erikson, D. L., and Pikitch, E. K. (1993). A histological description of shortspine thornyhead, Sebastolobus alascanus, ovaries: structures associated with the production of gelatinous egg mass. Environ. Biol. Fish. 36, 273-282. doi: 10.1007/BF00001723

Everson, A. R., Williams, H. A., and Ito, B. M. (1989). Maturation and reproduction in two Hawaiian eteline snappers, Uku, Aprion virescens, and Onaga, Etelis coruscans. Fish Bull. 87, 877-888.

Fishelson, L. (1975). Ethology and reproduction of Pteroid fishes found in the Gulf of Aqaba (Red Sea), especially Dendrochirus brachypterus (Cuvier), (Pteroidae, Teleostei). Pubbl. Staz. Zool. Napoli. 39, 635-656.

Fitzhugh, G. R., and Hettler, W. F. (1995). Temperature influence on postovulatory degeneration in Atlantic menhaden, Brevoortia tyrannus. Fish Bull. 93, 568-572.

Fordham, S. E., and Trippel, E. A. (1999). Feeding behaviour of cod (Gadus morhua) in relation to spawning. J. Appl. Ichthyol. 15, 1-9. doi: 10.1046/j.14390426.1999.00098.x

Frazer, T. K., Jacoby, C. A., Edwards, M. A., Barry, S. C., and Manfrino, C. M. (2012). Coping with the lionfish invasion: can targeted removals yield beneficial effects? Rev. Fish. Sci. 20, 185-191. doi: 10.1080/10641262.2012. 700655

Ganias, K., Vavalidis, T., Nunes, C., and Stratoudakis, Y. (2008). "Automating batch fecundity measurements using digital image analysis systems: a case study in the Iberian sardine," in Working Group on Acoustic and Egg Surveys for Sardine and
Anchovy in ICES Areas VIII and IX (Copenhagen: International Council for the Exploration of the Sea).

Golani, D., and Sonin, O. (1992). New records of the Red Sea fishes, Pterois miles (Scorpaenidae) and Pteragogus pelycus (Labridae) from the Mediterranean Sea. Jpn. J. Ichthyol. 39, 167-169.

Green, S. J., Akins, J. L., and Côté, I. M. (2011). Foraging behavior and prey consumption in the Indo-Pacific lionfish on Bahamian coral reefs. Mar. Ecol. Prog. Ser. 433, 159-167. doi: 10.3354/meps09208

Grier, H. J. (2012). Development of the follicle complex and oocyte staging in red drum, Sciaenops ocellatus Linnaeus, 1776 (Perciformes, Sciaenidae). J. Morphol. 273, 801-829. doi: 10.1002/jmor.20034

Grier, H. J., and Taylor, R. G. (1998). Testicular maturation and regression in the common snook. J. Fish Biol. 53, 521-542. doi: 10.1111/j.10958649.1998.tb00999.x

Grier, H. J., Uribe Aranzabal, M. C., and Patino, R. (2009). "The ovary, folliculogenesis, and oogenesis in teleosts," in Reproductive Biology and Phylogeny of Fishes, Vol. 8A, ed B. G. M. Jamieson (Enfield: Science Publishers), 25-84.

Hamner, R. M., Freshwater, D. W., and Whitfield, P. E. (2007). Mitochondrial cytochrome $b$ analysis reveals two invasive lionfish species with strong founder effects in the western Atlantic. J. Fish Biol. 71, 214-222. doi: 10.1111/j.10958649.2007.01575.x

Heyman, W. D., Kjerfve, B., Graham, R. T., Rhodes, K. L., and Garbutt, L. (2005). Spawning aggregations of Lutjanus cyanopterus (Cuvier) on the Belize Barrier Reef over a 6 year period. J. Fish Biol. 67, 83-101. doi: 10.1111/j.00221112.2005.00714.x

Hoar, W. S. (1969). "Reproduction," in Fish Physiology, eds W. S. Hoar and D. J. Randall (New York, NY: Academic Press), 287-321.

Hunter, J. R., and Macewicz, B. J. (1985). "Measurement of spawning frequency in multiple spawning fishes," in An Egg Production Method for Estimating Spawning Biomass of Pelagic Fish: Application to the Northern Anchovy, Engraulis Mordax, Vol. 36, ed R. Lasker (Springfield, VA: NOAA Tech. Rep. NMFS), 79-93.

Karlou-Riga, C., and Economidis, P. S. (1997). Spawning frequency and batch fecundity of horse mackerel, Trachurus trachurus, in the Saronikos Gulf (Greece). J. Appl. Ichthyol. 13, 97-104. doi: 10.1111/j.1439-0426.1997.tb0 0108.x

Koya, Y., and Muñoz, M. (2007). Comparative study on ovarian in scorpaenids: possible evolutionary process of reproductive mode. Ichthyol. Res. 54, 221-230. doi: 10.1007/s10228-006-0394-7

Kulbicki, M., Beets, J., Chabanet, P., Cure, K., Darling, E., Floeter, S. R., et al. (2012). Distributions of Indo-Pacific Pterois spp. in their native ranges: implications for the Atlantic invasion. Mar. Ecol. Prog. Ser. 446, 189-205. doi: 10.3354/meps09442

Lesser, M. P., and Slattery, M. (2011). Phase shift to algal dominated communities at mesotrophic depths associated with lionfish (Pterois volitans) invasion on a Bahamian coral reef. Biol. Invasions 13, 1855-1868. doi: 10.1007/s10530-0110005-Z

McBride, R. S., Snodgrass, D. J. G., Adams, D. H., Rider, S. J., and Colvocoresses, J. A. (2012). An indeterminate model to estimate egg production of the highly iteroparous and fecund fish, dolphinfish (Coryhaena hippurus). Bull. Mar. Sci. 88, 283-303. doi: 10.5343/bms.2011.1096

McBride, R. S., Stengard, F. J., and Mahmoudi, B. (2002). Maturation and diel reproductive periodicity of round scad (Carangidae: Decapterus punctatus) Mar. Biol. 140, 713-722. doi: 10.1007/s00227-001-0759-4

Morris, J. A. (2009). The Biology and Ecology of the Invasive Indo-Pacific lionfish. Dissertation, North Carolina State University, Raleigh.

Morris, J. A., and Akins, J. L. (2009). Feeding ecology of invasive lionfish (Pterois volitans) in the Bahamian archipelago. Environ. Biol. Fish. 86, 389-398. doi: 10.1007/s10641-009-9538-8

Morris, J. A., Shertzer, K. W., and Rice, J. A. (2011a). A stage-based matrix population model of invasive lionfish with implications for control. Biol. Invasions 13 , 7-12. doi: 10.1007/s10530-010-9786-8

Morris, J. A., Sullivan, C. V., and Govoni, J. J. (2011b). Oogenesis and spawn formation in the invasive lionfish, Pterois miles and Pterois volitans. Sci. Mar. 75 147-154. doi: 10.3989/scimar.2011.75n1147

Muñoz, M. (2001). Reproductive biology of some western Mediterranean scorpaeniformes (Teleostei). Cybium 25, 393-394.

Muñoz, M., Sàbat, M., Sílvia, V., and Casadevall, M. (2005). Annual reproductive cycle and fecundity of Scorpaena notata (Teleostei: Scorpaenidae). Sci. Mar. 69, $555-562$. 
Pandey, S., Parvez, S., Ansari, R. A., Ali, M., Kaur, M., Hayat, F., et al. (2008). Effects of exposure to multiple trace elements on biochemical, histological and ultrastructural features of gills of a freshwater fish, Channa punctata. Chem. Biol. Interact. 174, 183-192. doi: 10.1016/j.cbi.2008.05.014

Robertson, D. R. (1990). Differences in the seasonalities of spawning and recruitment of some small neotropical reef fishes. J. Exp. Mar. Biol. Ecol. 144, 49-62. doi: 10.1016/0022-0981(90)90019-9

Sakai, A. K., Allendorf, F. W., Holt, J. S., Lodge, D. M., Molofsky, J., With, K. A., et al. (2001). The population biology of invasive species. Annu. Rev. Ecol. Syst. 32, 305-332. doi: 10.1146/annurev.ecolsys.32.081501.114037

Sala, E., Aburto-Oropeza, O., Paredes, G., and Thompson, G. (2003). Spawning aggregations and reproductive behavior of reef fishes in the Gulf of California. Bull. Mar. Sci. 72, 103-121.

Schofield, P. J. (2009). Geographic extent and chronology of the invasion of nonnative lionfish (Pterois volitans [Linnaeus 1758] and P. miles [Bennett 1828]) in the Western North Atlantic and Caribbean Sea. Aquat. Invasions 4, 473-479. doi: 10.3391/ai.2009.4.3.5

Schofield, P. J., Morris, J. A., Langston, J. N., Fuller, P. L., and USGS-NAS. (2013) Pterois Volitans/Miles Point Map. Gainesville, FL: United States Geological Survey Nonindigenous Aquatic Species Database. Available online at: http:// nas2.er.usgs.gov/viewer/omap.aspx?SpeciesID=963 (Accessed Nov 15, 2013).

Taylor, M. H. (1984). Lunar synchronization of fish reproduction. Trans. Am. Fish. Soc. 113, 484-493.
Yoneda, M., Miura, H., Mitsuhashi, M., Matsuyama, M., and Matsuura, A. (2000) Sexual maturation, annual reproductive cycle, and spawning periodicity of the shore scorpionfish, Scorpaenodes littoralis. Environ. Biol. Fish. 58, 307-319. doi: 10.1023/A:1007627228435

Conflict of Interest Statement: The authors declare that the research was conducted in the absence of any commercial or financial relationships that could be construed as a potential conflict of interest.

Received: 10 September 2014; accepted: 30 January 2015; published online: 19 February 2015

Citation: Gardner PG, Frazer TK, Jacoby CA and Yanong RPE (2015) Reproductive biology of invasive lionfish (Pterois spp.). Front. Mar. Sci. 2:7. doi: 10.3389/fmars. 2015.00007

This article was submitted to Coral Reef Research, a section of the journal Frontiers in Marine Science.

Copyright (C) 2015 Gardner, Frazer, Jacoby and Yanong. This is an open-access article distributed under the terms of the Creative Commons Attribution License (CC BY). The use, distribution or reproduction in other forums is permitted, provided the original author(s) or licensor are credited and that the original publication in this journal is cited, in accordance with accepted academic practice. No use, distribution or reproduction is permitted which does not comply with these terms. 